\title{
STIRLING'S FORMULA REVISITED VIA SOME CLASSICAL AND NEW INEQUALITIES
}

\author{
Josef BuKac, TOMislav Burić AND NeVEn Elezović
}

Abstract. The Hermite-Hadamard inequality is used to develop an approximation to the logarithm of the gamma function which is more accurate than the Stirling approximation and easier to derive. Then the concavity of the logarithm of gamma of logarithm is proved and applied to the Jensen inequality. Finally, the Wallis ratio is used to obtain the additional term in Stirling's approximation formula.

Mathematics subject classification (2010): 26A51, 32F99, 41A17, 41A60.

Keywords and phrases: Stirling formula, Hermite-Hadamard inequality, Jensen inequality, Wallis ratio, approximation.

\section{REFERENCES}

[1] M. Abramowitz and I. A. Stegun (Eds), Handbook of Mathematical Functions with Formulas, Graphs, and Mathematical Tables, National Bureau of Standards, Applied Mathematics Series 55, 9th printing, Washington, 1970.

[2] H. Bateman, Higher Transcendental Functions, Volume 1, McGraw-Hill Book Co.Inc., New York, 1953.

[3] N. Batir, Very accurate approximations for the factorial function, J. Math. Inequal., (to appear)

[4] N. Batir, Sharp inequalities for factorial n, Proyecciones, 27(2008), no.1, 97-102.

[5] F. L. Bauer, Remark on Stirling's formulas and on approximations for the double factorial, Mathematical Intelligencer 28, 2 (2006), 10-21.

[6] T. Burić and N. Elezović, Bernoulli polynomials and asymptotic expansions of the quotient of gamma functions, J. Comput. Appl. Math (to appear)

[7] T. Burić and N. Elezović, New asymptotic expansions of the gamma function and improvements of Stirling's type formulas, J. Comput. Anal. Appl., (to appear)

[8] T. Burić and N. Elezović, New asymptotic expansions of the quotient of gamma functions, (submitted)

[9] W. Burnside, A rapidly convergent series for $\log N$ !, Messenger Math., 46 (1917), 157-159.

[10] N. Elezović, C. Giordano, J. Pečarić, The best bounds in Gautschi's inequality, Math. Inequal. Appl., 3 (2000), 239-252.

[11] W. Feller, Stirling's Formula. §2.9 in An Introduction to Probability Theory and Its Applications, Volume 1, 3rd ed., New York, 1968.

[12] G. M. Fichtengolc, Kurs diferencialnogo i integralnogo iscislenia, Tom II, (1966), Nauka, Moscow, (6th edition, in Russian).

[13] G. M. Fichtenholz, Differential Und Interalrechnung, Band 2, (1964), Deutscher Verlag Der Wissenschaften, Berlin.

[14] W. Gautschi, Inequalities for gamma and incomplete gamma function, J. Math. Phys., 39 (1959), $77-$ 81.

[15] D. Kershaw, Some extentions of W. Gautschi's inequalities for the gamma function, Math. Comp., 41 (1983), 607-611.

[16] P. Luschny, web address http://www.luschny.de/math/factorial/approx/SimpleCases.html

[17] C. Mortici, New approximations of the gamma function in terms of the digamma function, Appl. Math. Letters 23 (2010) 97-100. 
[18] C. Mortici, An ultimate extremely accurate formula for approximation of the factorial function, Arch. Math. (Basel), 93 (2009), no. 1, 37-45.

[19] C. Mortici, Best estimates of the generalized Stirling formula, Appl. Math. Comput., (2010), doi: 10.1016/j.amc.2009.12.013.

[20] C. Mortici, A new method for establishing and proving accurate bounds for the Wallis ratio, Math. Inequal. Appl., (to appear)

[21] C. P. Niculescu, L. E. Persson, Convex Functions and Their Applications, A Contemporary Approach, 2006, Springer.

[22] H. Robbins, A Remark of Stirling's Formula, Amer. Math. Monthly 62, 26-29, 1955.

[23] W. D. Smith, The Gamma function revisited, manuscript, 2006

[24] E. T. Whittaker, G. N. Watson, A Course of Modern Analysis, 1927, Cambridge University Press. 